\author{
Comentarios del libro Urinary Tract Infections: Molecular \\ Pathogenesis and Clinical Management. Second Edition, 2017 \\ Commentaries on the book Urinary Tract Infections: Molecular \\ Pathogenesis and Clinical Management. Second Edition, 2017
}

\title{
Estimado Editor
}

Nos dirigimos a Ud. y a los lectores de la Revista Virtual de SPMI para enviarle algunos comentarios sobre el libro Urinary Tract Infections: Molecular Pathogenesis and Clinical Management. Second Edition, 2017 Edited by Matthew A. Mulvey, David J. Klumpp and Ann E. Stapleton. Copyright ${ }^{\circ}$ American Society for Microbiology. ASM PRESS, Washington, DC.

\section{¿Qué contiene el texto?}

En sus 675 páginas el libro ofrece un panorama muy amplio y completo de las infecciones urinarias, que como su título lo indica, se extiende la patogénesis a nivel molecular hasta el manejo clínico de estas infecciones.

Los editores del libro, Mulvey MA, Klumpp DJ y Stapleton AE han sabido aglutinar a reconocidos profesionales dedicados al estudio de las infecciones urinarias de Estados Unidos, Canadá, Singapur, Suecia, Holanda, Alemania y Francia para la publicación de la Segunda Edición del texto. Esto provee un amplísimo panorama proveniente de varias naciones y universidades que en principio aseguran la riqueza del texto.

Es sabido que las infecciones de las vías urinarias (IVU) constituyen la segunda causa de infecciones en los seres humanos. El empleo de antibióticos es un tratamiento adecuado de estas infecciones, pero no previene las recurrencias. Es muy importante entonces conocer en detalle estas enfermedades, por su frecuencia pero también porque en numerosas ocasiones los tratamientos indicados según guías vigentes ${ }^{(1)}$ tiene una baja concordancia con los tratamientos indicados en atención primaria, tanto en la elección como en la duración de la administración del fármaco ${ }^{(2)}$.

El libro presenta las siguientes secciones: 1) aspectos clínicos de las infecciones urinarias 2) las bacterias uropatógenas, origen y mecanismos de la virulencia 3) respuestas del huésped a las infecciones del tracto urinario y terapéuticas emergentes.

La Primera Sección en sus ocho capítulos se refiere a los aspectos clínicos de las infecciones urinarias a los que los podemos considerar clásicos, es decir, la base clínica del diagnóstico y tratamiento de las IVU. Se presenta un pantallazo de la anatomía descriptiva y topográfica, rememorando conceptos de manera simple y concreta, enfocando conceptos actuales relacionados a la IVU, como por ejemplo las uroplaquinas, los tipos de adhesinas, elementos que cumplen un rol importante en estas infecciones. Desarrolla las presentaciones clínicas, los aspectos epidemiológicos y el diagnóstico, tratamiento y prevención de las IVU. Tiene también un capítulo dedicado a las infecciones urinarias en Pediatría y las infecciones en el varón, particularmente la prostatitis bacteriana. Se encuentran también en esta parte del texto, los conceptos de síndromes clínicos y definiciones empleadas en el manejo de las IVU.

Se consideran la clínica y el laboratorio en el diagnóstico de las IVU mediante métodos convencionales de cultivo, así como consideraciones sobre la estearasa leucocitaria y nitritos como guías para considerar la existencia de una infección. 
El libro ofrece también en su capítulo 8 un análisis exhaustivo de la sepsis a punto de partida urinario. Es importante dimensionar que en ocasiones las infecciones urinarias son capaces de generar compromisos sistémicos severos, poniendo incluso en riesgo la vida del paciente. De acuerdo al autor del capítulo, aproximadamente en 30\% de todos los pacientes sépticos, el foco infeccioso se localiza en el tracto urinario y se inicia en el parénquima de los órganos urogenitales, es decir, el riñón, la próstata o los testículos. Tengamos presente que la sepsis severa es una situación clínica crítica, con una mortalidad en el rango de 20 a $50 \%$ de los pacientes. Con relación al tratamiento se enfoca a los medicamentos utilizados en América del Norte y Europa, con resistencia a los mismos un tanto diferentes a las halladas en Latinoamérica.

Nos parece muy interesante esta primera parte del libro para los médicos que lidian con la asistencia de los pacientes, tanto en hospitales como en los consultorios.

En cuanto a la Segunda Sección, en los 12 capítulos que lo constituyen, examinan las bacterias uropatógenas y su virulencia, así como también presentan aspectos trascendentes tanto para los médicos asistencialistas, así como también para los investigadores.

El capítulo 10 presenta datos sobre el origen y la diseminación de las resistencias a los antibióticos, particularmente de Escherichia coli, continuando en los capítulos siguientes, con los factores de virulencia, las exotoxinas, los organelos que favorecen la adhesividad y las mutaciones de estas bacterias. Pero también tuvieron sus capítulos con numerosas referencias Proteus mirabilis, Klebsiella pneumoniae y otros gérmenes.

Culmina el capítulo con la fisiopatología integrada de las pielonefritis. A pesar de que los riñones son considerados como resistentes a las infecciones, se muestra en el texto cómo las bacterias finalmente comprometen al riñón.

La Tercera Sección contiene sólo 4 capítulos, enfoca las respuestas del huésped a las infecciones urinarias y las terapéuticas emergentes. Tengamos presente que las IVU son muy frecuentes, con 11 millones de casos reportados anualmente en Estados Unidos y un costo estimado que orilla los 5 billones de dólares americanos por año. Además de ser una afección común, es también altamente recurrente, con importante morbilidad. Esta alta incidencia y recurrencia de las IVU necesitan de nuevas drogas y vacunas para la prevención de estas infecciones. El último capítulo, que se refiere al desarrollo de vacunas para el tratamiento y prevención de las IVU, es apasionado porque resalta la necesidad de nuevas propuestas terapéuticas y vacunas para el manejo de esta afección.

\section{Recomponiendo el texto}

Luego del análisis de los datos presentados en el libro, nos parece importante destacar que el mismo contiene datos cuyo conocimiento permitirán afianzar la práctica clínica establecida e incluso mejorarla, lo que podría significar una importante mejoría en el cuidado del paciente y substanciales ahorros en gastos innecesarios. Además, el texto provee datos sobre las IVU que permitirán a los interesados proyectar investigaciones clínicas y básicas sobre la afección.

\section{¿Qué conclusiones podríamos proponerles?}

Ponemos a consideración de la comunidad médica del país la posibilidad de consultar este texto, que podría interesar a los microbiólogos, a médicos de familia, a los especialistas en Medicina Interna, a los pediatras, a los infectólogos, a los nefrólogos, a los urólogos, que están llamados en su práctica a responder adecuadamente al desafío permanente de diagnosticar, tratar, curar y prevenir las IVU.

Consideramos a la presente edición del libro como una fuente muy completa y actual de informaciones sobre las infecciones urinarias, cuyo adecuado manejo se podría vincular incluso a la disminución de la aparición de gérmenes multiresistentes en la comunidad. 
Por todo ello, permítanos recomendar esta obra a todos sus lectores.

Prof. Dra. Alejandra Walder

Primera Cátedra de Clínica Médica y Cátedra de Fisiopatología Facultad de Ciencias Médicas, Universidad Nacional de Asunción correo electrónico: alita_py@yahoo.com

Dra. Gladys Raquel Velázquez Aguayo

Departamento de Microbiología, Hospital de Clínicas, Facultad de Ciencias Médicas, Universidad Nacional de Asunción correo electrónico: velazquez.aguayo@gmail.com

Prof. Dr. Francisco Vicente Santa Cruz Segovia

Profesor de Fisiopatología y Clínica Médica

Facultad de Ciencias Médicas, Universidad Nacional de Asunción correo electrónico: fsantas@gmail.com

\section{REFERENCIAS BIBLIOGRÁFICAS}

1. Gupta K, Hooton TM, Naber KG, Wullt B, Colgan R, Miller LG, Moran GJ, Nicolle LE, Raz R, Schaeffer $A J$, Soper DE; Infectious Diseases Society of America; European Society for Microbiology and Infectious Diseases. International clinical practice guidelines for the treatment of acute uncomplicated cystitis and pyelonephritis in women: A 2010 update by the Infectious Diseases Society of America and the European Society for Microbiology and Infectious Diseases. Clin Infect Dis. 2011;52(5):e103-20.

2. Grigoryan L, Zoorob R, Wang H, Trautner BW. Low Concordance With Guidelines for Treatment of Acute Cystitis in Primary Care. Open Forum Infect Dis. 2015;2(4):ofv159. 